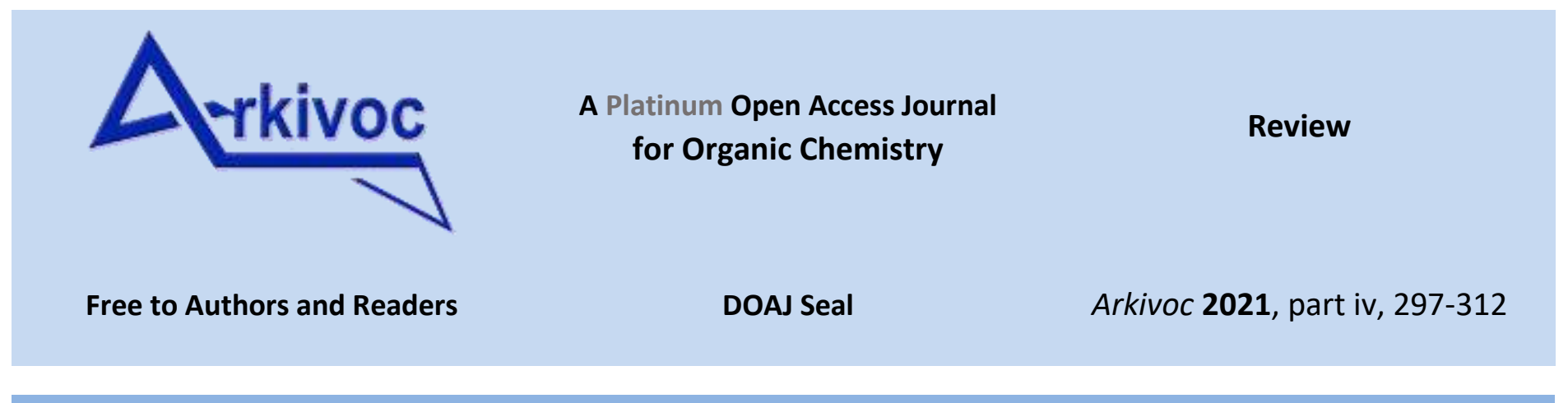

\title{
Multivalency effects in neuraminidase inhibitor design for influenza virus
}

\author{
Xuan Wei and Roland J. Pieters \\ Department of Chemical Biology \& Drug Discovery, Utrecht Institute for Pharmaceutical Sciences, Utrecht \\ University, Utrecht, The Netherlands \\ Email: R.J.Pieters@uu.nl
}

This article is dedicated to Professor Horst Kunz on the occasion of his $80^{\text {th }}$ birthday

Received 09-15-2020

Accepted 02-14-2021

Published on line 03-21-2021

\section{Abstract}

Multivalent interactions exist everywhere in nature. Here we will summarize the available data of multivalency effects that were explored for the design of novel neuraminidase (NA) inhibitors of influenza virus A. Although multivalency is a most effective tool to achieve high binding affinity, the molecular mechanisms are still poorly understood. The potency of multivalent neuraminidase inhibitors (NAIs) are dependent on the length, rigidity and chemical composition of the linker, ligand chemical structure and also the density of the ligand display. Important issues such as potential side-effects, drug-resistance, bioavailability and pharmacokinetics are largely unexplored with respect to application. The multivalent NAls reported so far were of surprising potency and may play a role in therapeutic application and may prove valuable in forecasted pandemics
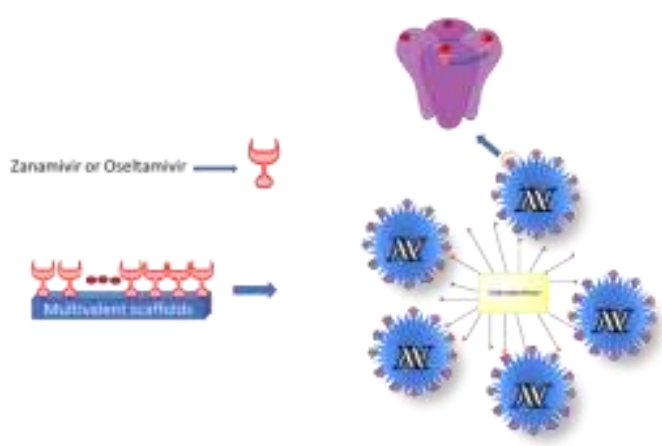

Keywords: Multivalency effects, neuraminidasae (NA), influenza virus, multivalent inhibitors 


\section{Table of Contents}

1. Introduction

2. Multivalent Inhibitors

3. Influenza Viruses

4. Current Strategies for Influenza Treatment

5. Multivalent Neuraminidase Inhibitors

6. Conclusions

Acknowledgements

References

\section{Introduction}

Multivalent interactions are often found in nature. They play a major role in biological processes for the selforganization of matter, recognition, adhesion, and signaling processes. Multivalent ligands have the potential to obtain higher specificity and affinity compared to their monovalent counterparts. Multivalent interactions are fundamental to many biological systems, including the recognition, adhesion and invasion of pathogens ${ }^{1}$ but also signal transduction and immune system activation. In the last few years multivalency effects have become increasingly of interest for the design of inhibitors for a range of pathogens including viruses, toxins, bacteria and fungi. These involve complex binding mechanisms to achieve noncovalent strong yet reversible interactions between multivalent ligands and multivalent receptors. ${ }^{2,3,4}$ Individual interactions are often weak, however, multiple simultaneous interactions between ligands and their receptors reinforce one-another like molecular velcro to achieve functionally enhanced binding affinity and increase specificity e.g. for bacterial adhesion inhibition. ${ }^{1}$ Currently, many researchers focus on harnessing this knowledge for the design and synthesis of multivalent inhibitors. Several studies demonstrated that multivalent inhibitors are effective agents for preventing viral infection. ${ }^{5,6,7}$ However, only few articles have reported the development of NAls that take advantage of multivalency. This review will give an overview of the multivalent effects in neuraminidase inhibition. The following sections describe the important principles underlying multivalency, the achievements of selected reported multivalent neuraminidase inhibitors and discusses the likely mechanistic basis of these effects.

\section{Multivalent Inhibitors}

Examples and proposed mechanisms of inhibitory enhancements by multivalent carbohydrates have been provided and reported in numerous studies. ${ }^{8,9,10,11}$ Since multivalent binding is especially effective to arrive at high-affinity ligands, multivalent ligands design has become a very active research domain. So, how do multivalent ligands enhance the potency of binding and inhibition? Several widely accepted mechanisms are shown in Figure 1 using a tetravalent ligand as an example. The first one is the so-called chelation mechanism (Figure 1b). The enhancement here is based on the reduction of entropic barriers when the binding of the second ligand occurs after the first (sub)ligand has bound. This is due to the fact that translational and rotational entropic penalties were already paid by the first binding event. In this case, a well-designed ligand with matched 
inter-binding-site distances can achieve a major enhancement in binding affinity of several orders of magnitude, as was seen for a divalent ligand targeting the LecA of lectin Pseudomonas aeruginosa. ${ }^{12}$

Another mechanism is named statistical rebinding, ${ }^{13,14,15}$ which is operational when the protein receptor has only one binding site or the multivalent ligand is too short to allow chelation (Figure 1c). The origin of the enhancement can be found in the notion that once the first ligand is released, the other (sub)ligands can immediately occupy the free position due to their close proximity. The resulting overall slower off-rate improves the binding affinity. Depending on the conditions and the degree of valency of the ligands, aggregation, ${ }^{16}$ and crosslinking can occur, which may be a cause or a consequence of multivalency effects.

a.

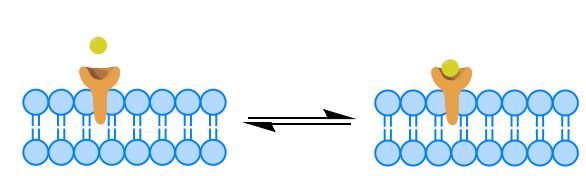

b.

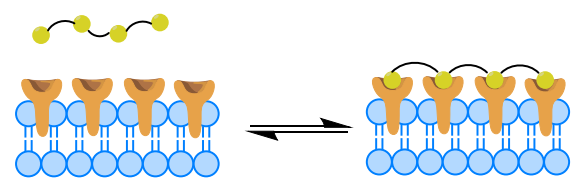

c.

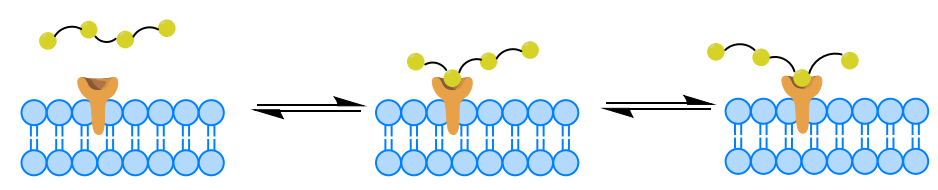

d.

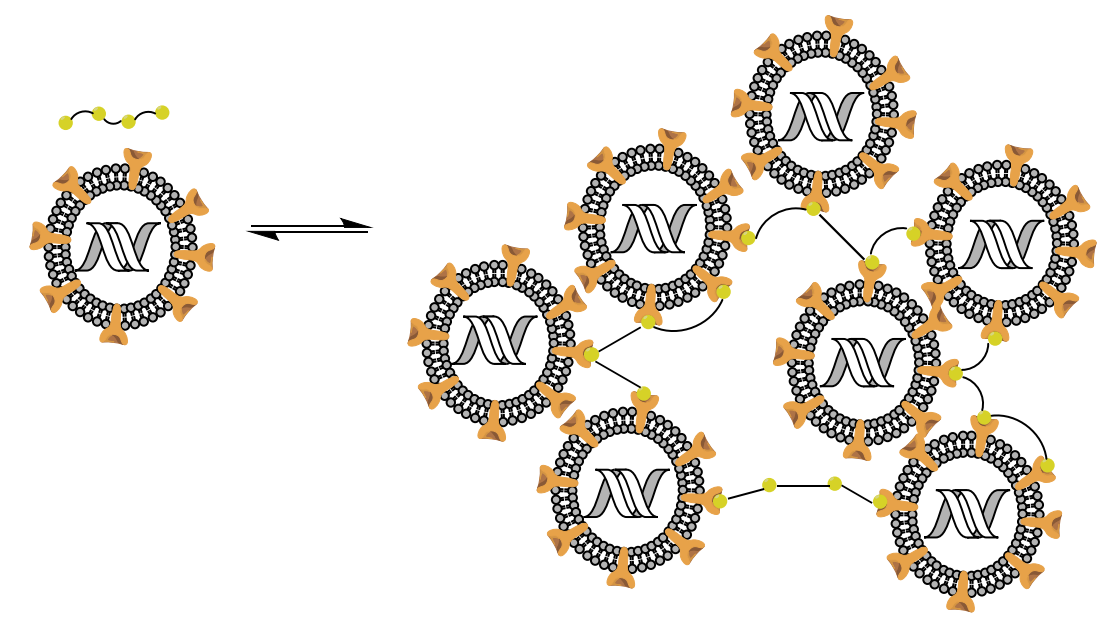

Figure 1. Mechanism of multivalent binding. a) monovalent binding; b) a tetravalent ligand and chelation mechanism; c) a tetravalent ligand and the statistical rebinding mechanism; d) tetravalent ligands involved in cross- linking or aggregation.

Multivalent systems are characterized by a discrete number of ligands with different conformational scaffolds. ${ }^{17,18,19,20}$ Previous studies on multivalent systems have reported numerous high-affinity ligands. They were based on combinations of monovalent ligands and connecting linkers. In this process, the structural architecture of ligands and linkers plays an important role. Here, we focus on the structure of the core linking units that can be divided into two categories: flexible and rigid central scaffolds. They are varied in terms of the valency, the size, and the spatial orientation of inhibitor. By altering the core dendrimer, polymer, peptide, protein, and nanoparticle, we can adjust the flexibility/rigidity of the central scaffold, and in cases produce highaffinity ligands and effective multivalent systems. 
For flexible linkers, their main characteristic is their high adaptability to the geometry of the protein. Over the past few year observations were made that this character can produce high-affinity multivalent ligands. Some flexible glycodendrimers and glycopolymers ${ }^{21}$ were reported as high potency inhibitors for type 1 fimbriated uropathogenic $E$. coli. All of these compounds showed enhanced affinity as compared to mannose with $\mathrm{IC}_{50}$ 's in the low micromolar range. Especially, the 16-valent glycodenrimer 1 (Figure 2) displayed the highest affinity $\left(\mathrm{IC}_{50}=19 \mu \mathrm{M}\right)$. The enhancement $(400$-fold over the monovalent ligand) was caused by the multiple copies of monovalent inhibitor and the flexible linkers enabled multiple binding events. Flexible glycodendritic linkers have been used as tools to study many pathogens and toxins, for example, the cholera toxin. In previous studies in our group highly effective dendrimers targeting CTB (cholera toxin B-subunit) were developed. The best dendrimer 2 showed a 47,500-fold improvement per GM1 oligosaccharide derivative compared to a monovalent reference compound. ${ }^{22,23}$ In the same period, Deguise et al. reported heterobifunctional glycodendrimers that can bind both Pseudomonas lectins LecA and LecB. ${ }^{24}$ Compound 3 can bind to both PA-IL and PA-IIL simultaneously. Interestingly, increasing the dendrimer generation did not cause further enhancement of binding beyond the octavalent.

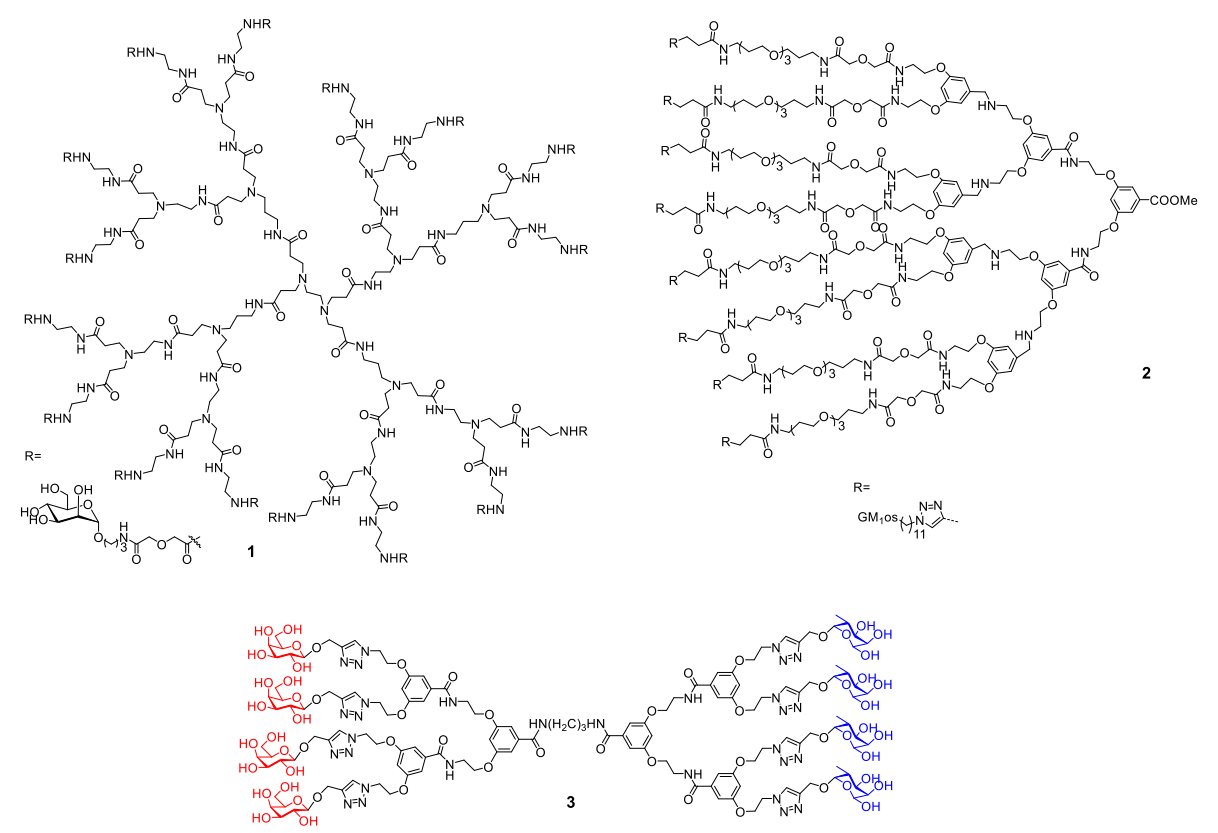

Figure 2. Molecular structures of multivalent ligands.

As alternatives to flexible linkers, inhibitors based on rigid components could create stronger binding, due to the reduced loss of conformational entropy during the multivalent binding. However, creating rigid architectures has many challenges, such as matching the topology of the protein. In recent years, with the improvement of structural analysis technology, we know more and more 3D structures of the pathogenic proteins and the location of the binding sites. This knowledge can help us to make more suitable inhibitors with increased rigidity. We explored rigid divalent ligands for the mentioned LecA protein and saw a strong preference for the correct length of the spacer as achieved for $\mathbf{4}$ and $\mathbf{5}$ with $\mathrm{K}_{d}$ 's in the low nanomolar ${ }^{12,25,26,27}$ (Figure 3 ) and the divalent binding mode was confirmed by X-ray crystallography. 
a)
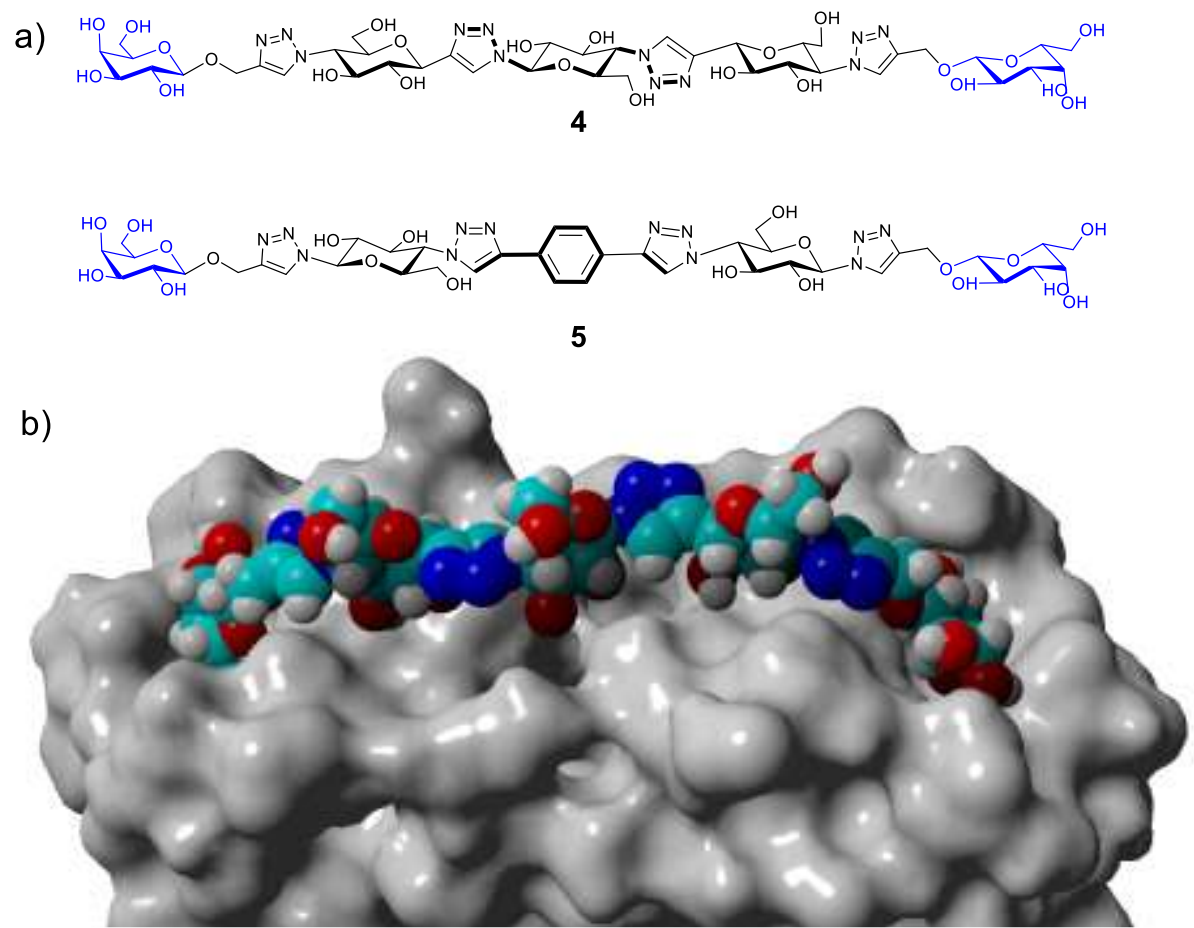

Figure 3. a) The structure of rigid divalent ligands for the LecA protein. b) X-ray structure of LecA complexed to 4 .

However back in $2003{ }^{28}$ we explored the inherently far more challenging task of synthesizing a rigid tetravalent compound linked to a lactose ligand for galectin binding. This compound 6 (Figure 4 ) showed an IC 50 of $0.07 \mu \mathrm{M}$ for mammalian galectin-3 with a relative potency of 4286 i.e. 1071 per sugar unit compared to monovalent lactose. It should be pointed out that in this case the enhancement was likely due to enhanced rebinding rather than chelation considering the divergent orientation of the binding sites. An efficient multivalent system as compound 7 for the inhibition of the hemagglutinin of the influenza $A$ virus, based on a rigid aromatic core, was also designed by our group. It was based on triphenylbenzene in the center and linked to extended LacNAcLac arms by CuAAC. The trivalent inhibitor shows significant affinity enhancement but the related molecule, lacking a single sialic acid, i.e. compound $\mathbf{8}$, effectively divalent was just as potent. ${ }^{6}$ Nevertheless as previously discussed, a well-designed divalent ligand can already make larger improvements on the order of three orders of magnitude. ${ }^{29,30}$ Sometimes, using flexible and rigid linkers together can also create a potent inhibitor. As an extension of that research a tetravalent ligand $\mathbf{9}$ was created that can aggregate multiple LecA tetramers in contrast to the divalent ligands it was based on. Even though the affinity did not increase the tetravalent ligand was a more potent biofilm blocker. ${ }^{31}$ 
6

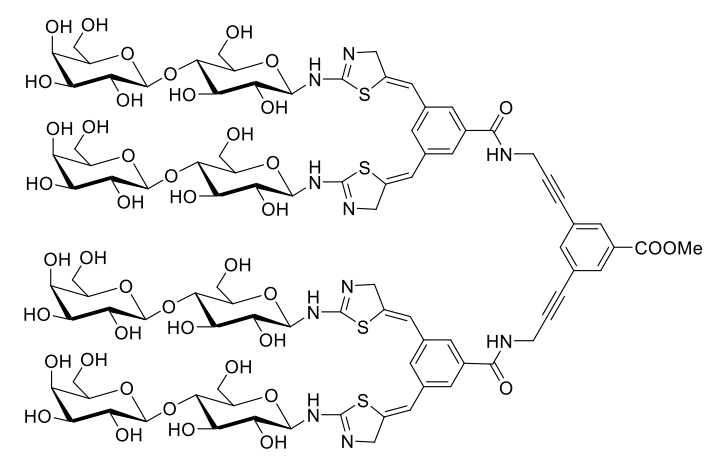

9
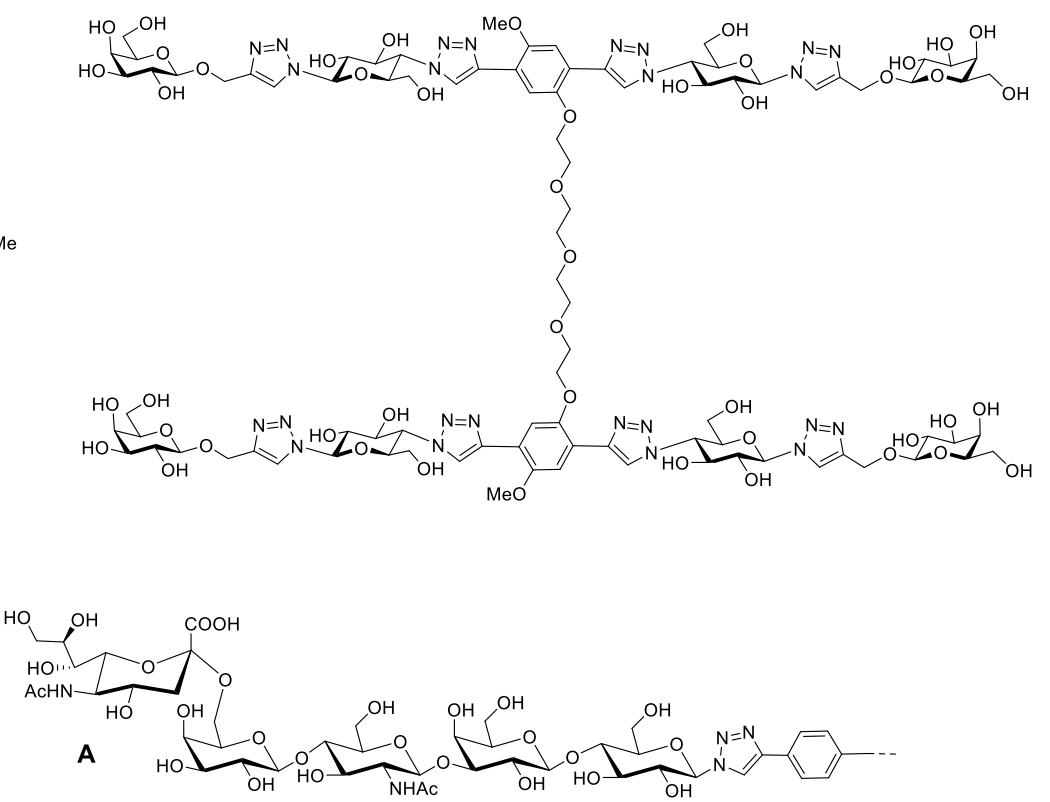

B

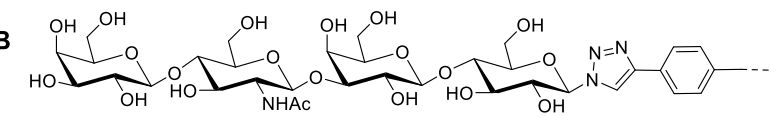

Figure 4. Structures of partially rigidified multivalent ligands.

\section{Influenza Viruses}

In history several flu pandemics have occurred such as ten years ago when millions of people were infected in more than 214 countries by S-OIV H1N1 (a new influenza virus). ${ }^{32,33}$ Influenza viruses belong to the family Orthomyxoviridae of enveloped viruses that have been classified into four types, A, B, C and the recently identified type D. ${ }^{34}$ All of them are enveloped negative-sense-single-strand RNA viruses with a segmented genome. The influenza A virus and B virus both contain hemagglutinin (HA) and neuraminidase (NA) proteins on their surface. Interestingly, influenza $C$ virus and $D$ virus carry the haemagglutinin-esterase-fusion protein, which combines both the function of HA and NA. ${ }^{35,36,37} \mathrm{HA}$ and NA are the two main tools for type A and type B viruses to initiate an infection by their interaction with sialic acid (SA) at the cell surface. ${ }^{38} \mathrm{HA}$ can be seen as a Velcro cover where multiple flexible hooks interact with the cell surface, enabling attachment and entry of virus. Compared to HA, NA can be seen as a pair of scissors, only responsible for release of progeny virions from the host cell. ${ }^{39}$ However, many studies reported that NA may play other roles in the early stages of the viral life cycle.

\section{Current Strategies for Influenza Treatment}

Influenza virus makes a comeback every year that causes a loss of productivity and poses a serious threat to world economies. ${ }^{40}$ So far, vaccines and antibody therapies are representing the most efficient way to reduce the influenza impact. ${ }^{41}$ Two type vaccines are licensed: 1 ) Inactivated influenza vaccines (IIV), which is approved 
for use in persons 6 months and older. 2) Live attenuated influenza vaccines (LAIV), which is approved for use only in persons aged 2-49 years who do not have underlying medical conditions, and it cannot be used by pregnant women. The influenza viruses, can evade pre-existing immunity by varying continuously through antigenic drifts and occasional antigenic shifts and have the potential to cause another pandemic. ${ }^{42}$ Worse, in the initial months of an influenza pandemic, it is impossible to develop specific and effective vaccines and produce them at scale. ${ }^{43}$

As an alternative, antiviral drugs have been offered as an important option to combat influenza infections. The first available drugs that appeared on the market were the adamantanes. The adamantanes including amantadine and rimantadine, target the $\mathrm{M} 2$ channel, thereby interrupting the fusion and uncoating process during the early stages of viral replication. However, they are no longer recommended because the lack of activity against type $B$ influenza, the risk of neurotoxicity and the rapid development of drug resistance. ${ }^{44}$ In contrast, Neuraminidase inhibitors (NAIs) have been proven to be safe and effective in reducing influenza severity, duration of symptoms, hospitalizations, and influenza-related-mortality. NAls are effective against influenza type $A$ and type $B$, as the structure of the neuraminidase active site is highly conserved among all subtypes. ${ }^{45}$ Four NAls are approved for treatment: zanamivir and oseltamivir globally, and peramivir and laninamivir in Japan, China and South Korea. Oseltamivir is the most used therapeutic, in part due to its convenient oral administration. ${ }^{46}$ However, drug resistance has also emerged for some NAls. Other compounds (Figure 5) have been used to solve this problem. Baloxavir (10) is an oral-antiviral drug for curing influenza A and B, which has been approved only in the United States and Japan in 2018. Its mechanism of action is different from oseltamivir and zanamivir. It targets the endonuclease function of the PA polymerase subunit to inhibit the cap-snatching process, which is an important process for the transcription of viral mRNA. ${ }^{47}$ Favipiravir (11) is used to inhibit the synthesis of viral mRNA. It prevents the elongation of the mRNA chain at its incorporated site. ${ }^{48}$ Recently, Favipiravir has received limited approval in Japan for the treatment of novel or re-emerging influenza infections with poor treatment options. A number of novel antiviral agents, including nitazoxanide (12) and DAS181 (13, a recombinant fusion protein), are also under evaluation. ${ }^{49}$ Notably, DAS181 does not work like an inhibitor but more like a reaper. As a sialidase it can remove both $\alpha(2,3)$ - and $\alpha(2,6)$-linked sialic acids from the cell surface, thus preventing HA from binding. ${ }^{50}$ 


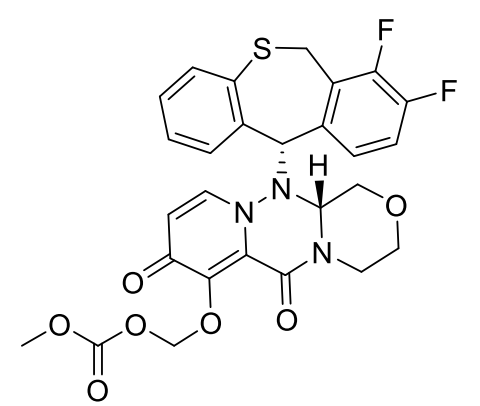

Baloxavir marboxil 10

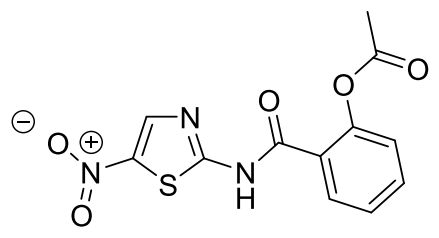

Nitazoxanide 12

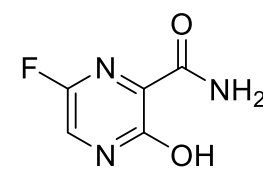

Favipiravir 11

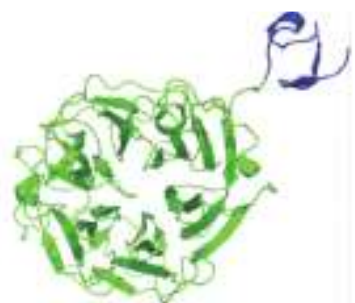

Molecular model of DAS181, 13

Figure 5. Structures of other known ligands 10-12 and a model of DAS181 13 . The catalytic domain of the sialidase is shown in green.

\section{Multivalent Neuraminidase Inhibitors}

In the 1970s, the influenza neuraminidase (NA) was discovered as a potential drug target. The first known inhibitor that was a transition state analogue, i.e. 2,3-didehydro-2-deoxy-N-acetylneuraminic acid (DANA). It has a good inhibitory effect in vitro, but it failed in animal models. ${ }^{51}$ Subsequent inhibitors based on the sialic acid structure were synthesized that also showed good activity in vitro, ${ }^{52}$ but bioavailability was found to be a problem. Then the crystal structure of NA was solved revealing how the tetramer could have identical subunits and no enzyme activity as a monomer. The four binding sites made NA a very interesting target for multivalent structure-based drug design. In 2004, Macdonald, et al. synthesized dimeric Zanamivir derivatives linked through the C7 hydroxyl with flexible linkers (length range from 8 to 59 atoms). They showed the importance of an optimal length. The inhibitory potency of the dimers (compound 14 and 15) with linking groups of 14 to 18 atoms in length, were approximately 100-fold higher in vitro and in vivo than zanamivir. Especially, the linker length of 18 to $22 \AA$ showed an outstanding long-lasting protective activity in mouse influenza infectivity experiments. This indicated that the dimers benefitted from multivalency likely via intertetramer and intervirion linkages, as the distances between binding sites of a single tetramer were far larger. ${ }^{53}$ In futher studies, they investigated a range of linking groups with different physicochemical properties which lead to 16 and 17 . Like 14, these two dimers showed outstanding activity in a 1-week mouse influenza prophylaxis assay. High concentration of dimers was found remaining in rat lung tissue after 1 week. ${ }^{54}$ As the monovalent entity, Zananivir derivatives are so far preferred. The 7-hydroxyl group of zanamivir was suitable for further modification and crosslinking without interfering with the activity of the compound. To further explore the multivalent binding aspects scientists also investigated trimeric, tetrameric and polymeric zanamivir derivatives. Waston and coworkers ${ }^{55}$ designed a set of trimeric and tetrameric derivatives of zanamivir synthesized by coupling a common monomeric zanamivir derivative onto various multimeric carboxylic acid core groups. The resulting multimeric compounds $\mathbf{1 8 - 2 3}$ all showed at least 40-fold enhanced antiviral activity than zanamivir and 
also showed outstanding long-lasting protective activity when tested in mouse influenza infectivity experiments. The results also indicated that within a series of similarly spaced compounds various scaffold architectures are well tolerated. The data of a CPE inhibition assay showed that the tetrameric compounds (22 and 23) had similar activity as the trimeric compounds (18-21). As was the case for the mentioned dimers, the distance between the NA active sites is too long to be covered by the spacers and scaffolds, so chelation is not the origin of the observed effects. Similarly, Yang et al. ${ }^{56}$ synthesized mono-, di-, tetra-, and octa-valent difluorinated zanamivir analogs (DFSAs) 24-29 in 2016. They evaluated the inhibitory activity of those zanamivir analogs in various assays. The best multivalent sialoside was $\mathbf{2 9}$, which enhanced inhibition $\mathbf{1 4 5}$-fold over monomer $\mathbf{3 0 b}$. With the use of the structural knowledge of NA and their tetrameric spatial arrangement, Fu, et al. ${ }^{57}$ have developed a tetravalent zanamivir (TZ) molecule 31. This compound showed essentially no enhancement in NA inhibition over zanamivir. However, in an SPR binding assay it was shown that $\mathbf{3 1}$ bound a mutant N2 over a 1000-fold more strongly than monovalent zanamivir with a sub-picomolar $\mathrm{K}_{\mathrm{d}}$. Some effects also translated to in vivo experiments where it was shown that a single dose of $20 \mathrm{mg}$ of $\mathbf{3 1}$ saved all mice whereas 20 mg zanamivir was not able to save the mice. Considering the long flexible spacers, it is geometrically conceivable that four zanamivir residues simultaneously bound to all four monomers of NA, which requires distances of ca. $38 \AA$ from the center of the molecule including part of the core and the ligand. A 12 PEG unit may have its distance optimum at $20 \AA{ }^{58}$ but considering its flexibility some of molecules will easily span the ca. 28 angstrom between core and ligand. This notion is supported by the fact that no binding enhancement was seen in case shorter PEG spacers were used.

Besides the mentioned low valent examples a few polymeric NA Inhibitors were also reported (Figure 7). In 2002, The C-7 of zanamivir was used as an attachment site for the synthesis of poly-L-glutamic acid based polyvalent inhibitors by Honda's group such as 33. ${ }^{59}$ Even though in the enzyme inhibition assay the glycopolymers were less potent than monovalent zanamivir derivatives such as 32, in plaque reduction assay the polymers were up to ca. two orders of magnitude more potent. This observation extended to an in vivo study where the glycopolymer lead to a total survival of the infected mice in contrast to the zanamivir treated mice which mostly did not survive. In 2010, Haldar et al. synthesized a bifunctional polymer 34 which contained both 07-linked zanamivir and also 2-linked sialic acid as well as the corresponding mono-functionalized polymers $\mathbf{3 5}$ and $\mathbf{3 6}$. In a plaque reduction assay they found a major improvement of the homopolymers over the monovalent compounds, where the zanamivir containing polymer (36) showed good inhibition with an IC 50 of $22 \mathrm{nM}$. Intriguingly, the polymer which both components (34) were more potent than 36 with just the zanamivir derivative, with an $\mathrm{IC}_{50}$ of $1.3 \mathrm{nM}$. The authors suggested that the presence of the sialic acid derivatives may play a role in HA mediated viral adhesion as well, thus leading to a combination effect of blocking both viral proteins. ${ }^{60}$ 


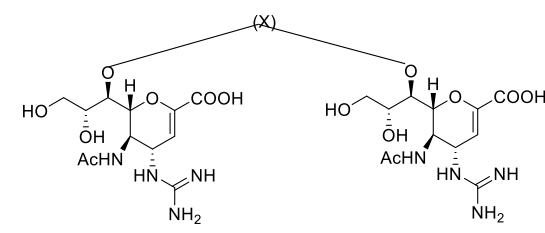

$\mathrm{X:14}=\mathrm{CONH}\left(\mathrm{CH}_{2}\right)_{12} \mathrm{NHCO}$ $\mathbf{1 5}=\mathrm{CONH}\left(\mathrm{CH}_{2}\right){ }_{14} \mathrm{NHCO}$<smiles>[R]C(=O)c1cc(C([R])=O)cc(C([R])=O)c1</smiles>

18

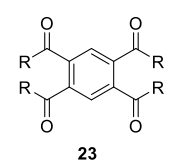

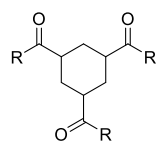

19
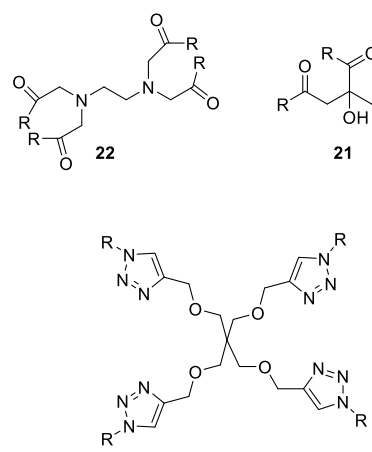

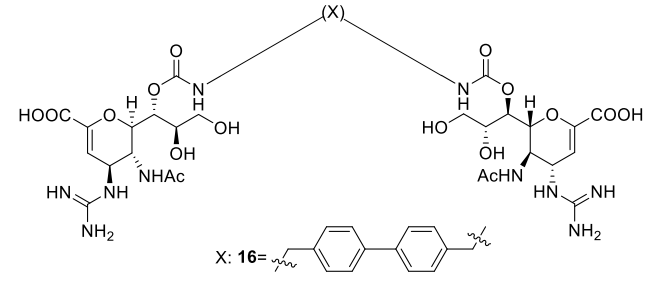

$17=\cdots\left(\mathrm{H}_{2} \mathrm{C}\right)_{3} \mathrm{HNOC}-\longrightarrow \mathrm{CONH}\left(\mathrm{CH}_{2}\right)_{3} \cdots$
24: $R=0$

25: $R=0$

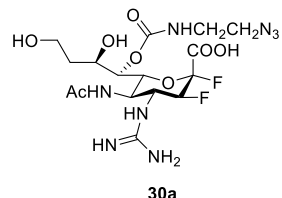

$30 \mathrm{a}$

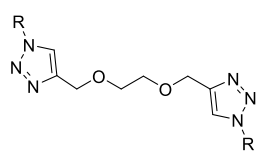

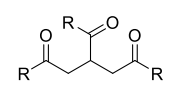

20
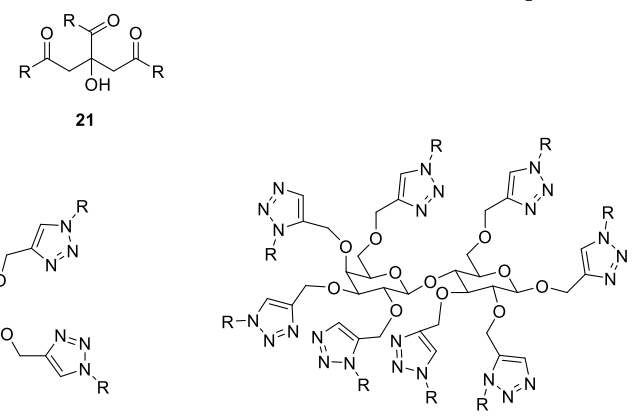

28: $R=0$

29: $R=0$
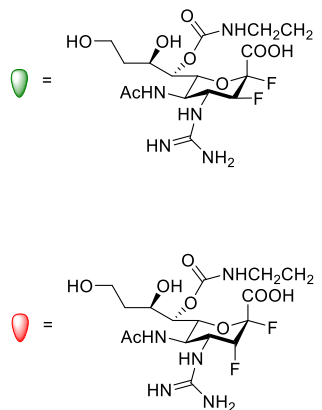

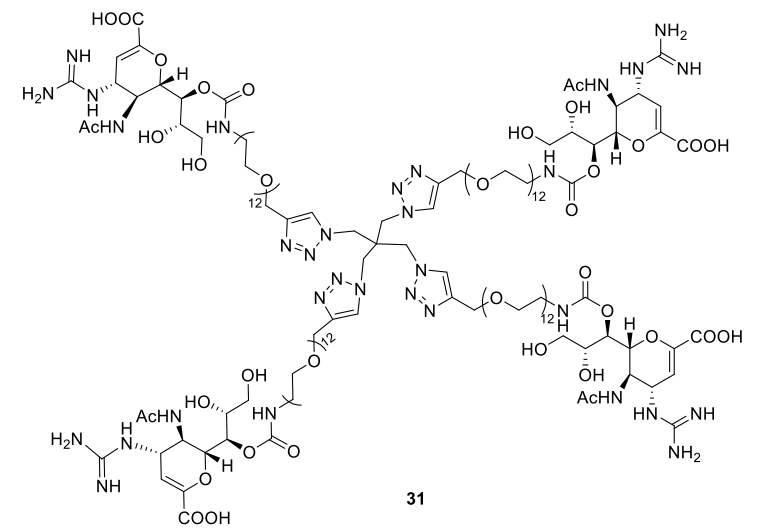

Figure 6. Multivalent NA inhibitors. 

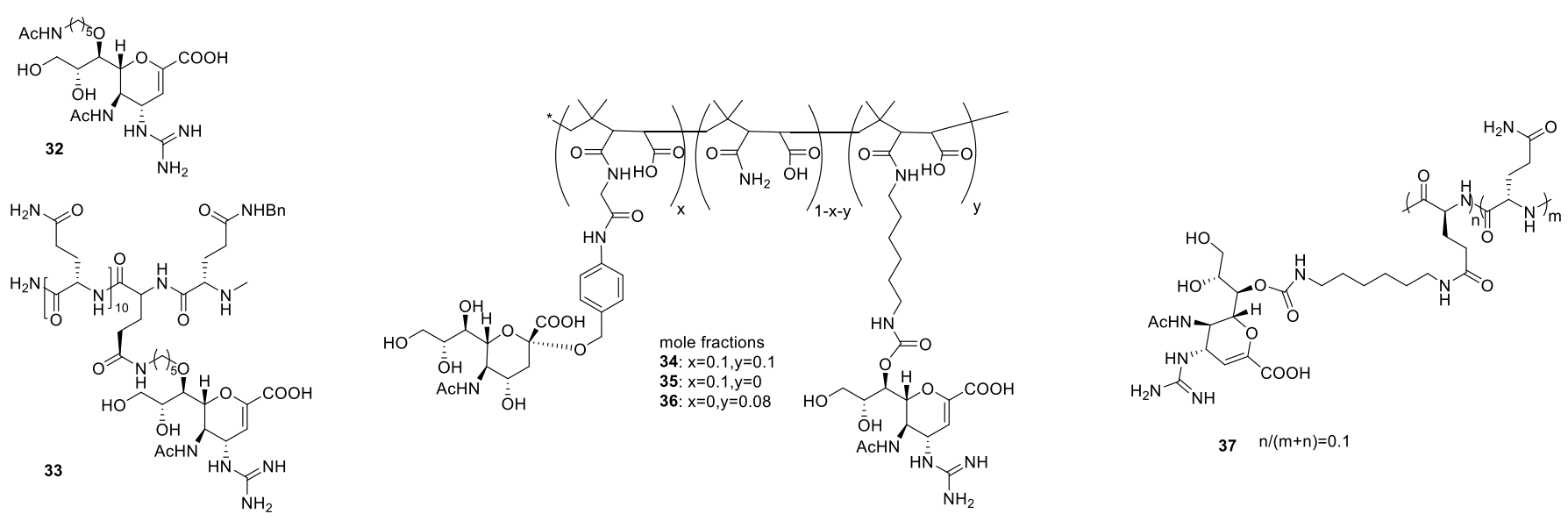

Figure 7. Polymeric NA Inhibitors. In the depicted structure, $n, m, x$ and $y$ are the mole-fractions.

Similarly, Weight et al. attached Zanamivir to poly-L-glutamine, obtained major improvement against both wild-type flu virus and drug-resistant mutants. The optimal compound $\mathbf{3 7}$ showed a 20,000-fold anti-influenza enhancement in a plaque reduction assay compared with monovalent zanamivir derivative for the inhibition of the human influenza strain Wuhan. ${ }^{61}$

\section{Conclusions}

So far, Oseltamivir and Zanamivir are the most prominent drugs being used to treat influenza infections. They are monomeric neuraminidase inhibitors that suffer from varying degrees of drug resistance. The resistance creates an urgent situation and a need to look for solutions. Multivalent interactions play an important role in influenza infections and multivalent neuraminidase inhibitors may be a direction to tackle the resistance problem. While some compounds have shown promising effects, optimization is necessary. Thus optimization would be facilitated if the multivalency mechanism is known. Therefore, it is necessary to know the unique interactions on the molecular level and then develop optimized multivalent ligands to achieve strong inhibitory effects. Neuraminidase is a tetrameric protein, distributed on the surface of the influenza virus envelope and involved in influenza virus infection in both virus attaching and detaching processes. This makes it binds well to most multivalent systems. Divalent zanamivir molecules of specific length were found to be optimal inhibitors while both shorter and longer systems seem to be worse. These dimers are too short to bridge between binding sites within a tetramer so their mechanism is not clear. Statistical rebinding is a possibility as well as aggregation of NA tetramers or whole virus particles. The fact is that these molecules are not good at inhibiting the enzymatic activity of the NA enzyme, but show their efficacy in infection assays where they have greater potency, and stay present in the tissues much longer than their monovalent counterparts. Further optimization is needed. Fu et al. were the first to show a tetramer that has the potential to bind all four binding sites of NA and seems successful. Molecules of this type should be studied more and as well as their mode of action compared with the divalent molecules. All of these molecules are likely small enough to become a drug. This may be more difficult for glycopolymers or neoglycoproteins. Nevertheless this class has yielded some very interesting and potent compounds. Besides potency, the use of HA and NA targeting within the same molecule has shown promise and can readily be achieved within a single construct. At this stage it is of great interest to further develop multivalent NA inhibitors as we have only seen a glimpse of their potential. Whether the 
divalent, tetravalent or higher valent prove to be the most effective in the end, no-one knows. However it is clear that new and potent flu treatments are needed as viral pandemics can suddenly become a reality.

\section{Acknowledgements}

XW gratefully acknowledges financial support by a scholarship from the China Scholarship Council CSC, http://www.csc.edu.cn/), file no. 201606230221.

\section{References}

1. (1) Roland, J.; Pieters, R. J. Adv. Exp. Med. Biol. 2011, 715, 227-240. https://doi.org/10.1007/978-94-007-0940-9 14

2. Fasting, C.; Schalley, C. A.; Weber, M.; Seitz, O.; Hecht, S.; Koksch, B.; Dernedde, J.; Graf, C.; Knapp, E.-W.W.; Haag, R. Angew. Chem. Int. Ed. Engl. 2012, 51 (42), 10472-10498.

https://doi.org/10.1002/anie.201201114

3. Kiessling, L. L.; Grim, J. C. Chem. Soc. Rev. 2013, 42 (10), 4476-4491. https://doi.org/10.1039/c3cs60097a

4. Ting, S. R. S.; Chen, G.; Stenzel, M. H. Polymer Chemistry. 2010, 1, 1392-1412. https://doi.org/10.1039/c0py00141d

5. Wittmann, V.; Pieters, R. J. Chem. Soc. Rev. 2013, 42 (10), 4492-4503. https://doi.org/10.1039/c3cs60089k

6. Lu, W.; Du, W.; Somovilla, V. J.; Yu, G.; Haksar, D.; de Vries, E.; Boons, G.-J.; de Vries, R. P.; de Haan, C. A. M.; Pieters, R. J. J. Med. Chem. 2019, 62, 6398-6404.

https://doi.org/10.1021/acs.jmedchem.9b00303

7. Kim, H. C.; Oh, D. S.; Park, J. H.; Kim, H. J.; Seo, Y. B.; Yoo, H. J.; Jang, H. S.; Shin, J.; Kim, C. W.; Kwon, M. S.; Jin, H. T.; Lee, S. K.; Oh, J. E.; Lee, H. K. Antiviral Res. 2020, 177, 104755.

https://doi.org/10.1016/j.antiviral.2020.104755

8. Pieters, R. J. Org. Biomol. Chem. 2009, 7 (10), 2013-2025. https://doi.org/10.1039/b901828j

9. Choi, H.; Jung, Y. Chem. Eur. J. 2018, 24 (72), 19103-19109. https://doi.org/10.1002/chem.201801408

10. Liu, J.; Begley, D.; Mitchell, D. D.; Verlinde, C. L. M. J.; Varani, G.; Fan, E. Chem. Biol. Drug Des. 2008,71 (5), 408-419.

https://doi.org/10.1111/i.1747-0285.2008.00648.x

11. Lundquist, J. J.; Debenham, S. D.; Toone, E. J. J. Org. Chem. 2000, 65 (24), 8245-8250. https://doi.org/10.1021/jo000943e

12. (Pertici, F.; Mol, N. J. De; Kemmink, J.; Pieters, R. J.; de Mol, N. J. Chem. Eur. J. 2013, 19 (50), $16923-16927$. https://doi.org/10.1002/chem.201303463

13. Kiessling, L. L.; Gestwicki, J. E.; Strong, L. E. Angew. Chem. Int. Ed. Engl. 2006, 45 (15), 2348-2368. https://doi.org/10.1002/anie.200502794

14. Gestwicki, J. E.; Cairo, C. W.; Strong, L. E.; Oetjen, K. A.; Kiessling, L. L. J. Am. Chem. Soc. 2002, 124 (50), 14922-14933. 
https://doi.org/10.1021/ja027184x

15. Quesenberry, M. S.; Lee, R. T.; Lee, Y. C. Biochemistry 1997, 36 (9), 2724-2732.

https://doi.org/10.1021/bi9622635

16. Bhatia, S.; Camacho, L. C.; Haag, R. J. Am. Chem. Soc. 2016, 138 (28), 8654-8666.

https://doi.org/10.1021/jacs.5b12950

17. Wolfenden, M. L.; Cloninger, M. J. Bioconjug. Chem. 2006, 17 (4), 958-966.

https://doi.org/10.1021/jacs.5b12950

18. André, S.; Cejas Ortega, P.; Ferez, M. A.; Roy, R.; Gabius, H. J. Glycobiology 1999, 9 (11), 1253-1261. https://doi.org/10.1093/glycob/9.11.1253

19. Ashton, P. R.; Boyd, S. E.; Brown, C. L.; Jayaraman, N.; Stoddart, J. F. Angew. Chemie Int. Ed. English 1997, 36 (7), 732-735.

https://doi.org/10.1002/anie.199707321

20. (Arce, E.; Nieto, P. M.; Diaz, V.; Castro, R. G.; Bernad, A.; Rojo, J. Bioconjug. Chem. 2003, 14 (4), $817-823$. https://doi.org/10.1021/bc034008k

21. Appeldoorn, C. C. M.; Joosten, J. A. F.; el Maate, F. A.; Dobrindt, U.; Hacker, J.; Liskamp, R. M. J.; Khan, A. S.; Pieters, R. J.; Ait El Maate, F.; El Maate, F. A. Tetrahedron Asymmetry 2005, 16 (2), 361-372. https://doi.org/10.1016/j.tetasy.2004.11.014

22. Pukin, A. V; Branderhorst, H. M.; Sisu, C.; Weijers, C. C. A. G. M.; Gilbert, M.; Liskamp, R. M. J.; Visser, G. M.; Zuilhof, H.; Pieters, R. J. ChemBioChem 2007, 8, 1500-1503.

https://doi.org/10.1002/cbic.200700266

23. Zomer-van Ommen, D. D.; Pukin, A. V.; Fu, O.; Quarles van Ufford, L. H. C.; Janssens, H. M.; Beekman, J. M.; Pieters, R. J. J. Med. Chem. 2016, 59 (14), 6968-6972.

https://doi.org/10.1021/acs.jmedchem.6b00770

24. Deguise, I.; Lagnoux, D.; Roy, R. New J. Chem. 2007, 31 (7), 1321-1331. https://doi.org/10.1039/b701237c

25. Pertici, F.; Pieters, R. J. Chem. Commun. 2012, 48 (33), 4008-4010. https://doi.org/10.1039/c2cc30234a

26. Visini, R.; Jin, X.; Bergmann, M.; Michaud, G.; Pertici, F.; Fu, O.; Pukin, A.; Branson, T. R.; Thies-Weesie, D. M. E.; Kemmink, J.; Gillon, E.; Imberty, A.; Stocker, A.; Darbre, T.; Pieters, R. J.; Reymond, J.-L. ACS Chem. Biol. 2015, 2455-2462. https://doi.org/10.1021/acschembio.5b00302

27. Yu, G.; Vicini, A. C.; Pieters, R. J. J. Org. Chem. 2019, 84, 2470-2488. https://doi.org/10.1021/acs.joc.8b02727

28. Vrasidas, I.; André, S.; Valentini, P.; Böck, C.; Lensch, M.; Kaltner, H.; Liskamp, R. M. J.; Gabius, H.-J. J.-J.; Pieters, R. J.; Andre, S.; Bock, C.; André, S.; Bock, C. Org. Biomol. Chem. 2003, 1 (5), 803-810. https://doi.org/10.1039/b210923a

29. Pukin, A. V.; Brouwer, A. J.; Koomen, L.; Quarles van Ufford, H. C.; Kemmink, J.; de Mol, N. J.; Pieters, R. J. Org. Biomol. Chem. 2015, 13, 10923-10928.

https://doi.org/10.1039/C5OB01452B

30. Fu, O.; Pukin, A. V.; Quarles van Ufford, H. C.; Kemmink, J.; de Mol, N. J.; Pieters, R. J. ChemistryOpen 2015, 4 (4), 463-470. https://doi.org/10.1002/open.201402171

31. Yu, G.; Thies-Weesie, D. M. E.; Pieters, R. J. Helv. Chim. Acta 2019, 102 (3), 1-8. https://doi.org/10.1002/hlca.201900014 
32. Singh, N.; Anjum, N.; Chandra, R. Phytochem. Rev. 2019, 18 (1), 69-107. https://doi.org/10.1007/s11101-018-9581-1

33. Garten, R. J.; Davis, C. T.; Russell, C. A.; Shu, B.; Lindstrom, S.; Balish, A.; Sessions, W. M.; Xu, X.; Skepner, E.; Deyde, V.; Okomo-Adhiambo, M.; Gubareva, L.; Barnes, J.; Smith, C. B.; Emery, S. L.; Hillman, M. J.; Rivailler, P.; Smagala, J.; De Graaf, M.; Burke, D. F.; Fouchier, R. A. M.; Pappas, C.; Alpuche-Aranda, C. M.; López-Gatell, H.; Olivera, H.; López, I.; Myers, C. A.; Faix, D.; Blair, P. J.; Yu, C.; Keene, K. M.; Dotson, P. D.; Boxrud, D.; Sambol, A. R.; Abid, S. H.; St. George, K.; Bannerman, T.; Moore, A. L.; Stringer, D. J.; Blevins, P.; Demmler-Harrison, G. J.; Ginsberg, M.; Kriner, P.; Waterman, S.; Smole, S.; Guevara, H. F.; Belongia, E. A.; Clark, P. A.; Beatrice, S. T.; Donis, R.; Katz, J.; Finelli, L.; Bridges, C. B.; Shaw, M.; Jernigan, D. B.; Uyeki, T. M.; Smith, D. J.; Klimov, A. I.; Cox, N. J.. Science, 2009, 325 (5937), 197-201.

https://doi.org/10.1126/science.1176225

34. Du, R.; Cui, Q.; Rong, L. Viruses 2019, 11 (5), 1-13.

https://doi.org/10.3390/v11050458

35. Zhang, W.; Zhang, L.; He, W.; Zhang, X.; Wen, B.; Wang, C.; Xu, Q.; Li, G.; Zhou, J.; Veit, M.; Su, S. Viruses 2019, 11 (2), 167.

https://doi.org/10.3390/v11020167

36. Su, S.; Fu, X.; Li, G.; Kerlin, F.; Veit, M. Virulence 2017, 8 (8), 1580-1591. https://doi.org/10.1080/21505594.2017.1365216

37. Rosenthal, P. B.; Zhang, X.; Formanowski, F.; Fitz, W.; Wong, C. H.; Meier-Ewert, H.; Skehel, J. J.; Wiley, D. C. Nature 1998, 396 (6706), 92-96. https://doi.org/10.1038/23974

38. Matrosovich, M.; Herrler, G.; Klenk, H D. Top. Curr. Chem. 2015, 367, 1-28. https://doi.org/10.1007/128 2013466

39. McAuley, J. L.; Gilbertson, B. P.; Trifkovic, S.; Brown, L. E.; McKimm-Breschkin, J. L. Front. Microbiol. 2019, 10, 26-32.

https://doi.org/10.3389/fmicb.2019.00039

40. Yang, J.; Liu, S.; Du, L.; Jiang, S. Rev. Med. Virol. 2016, 26 (4), 242-250.

https://doi.org/10.1002/rmv.1879

41. Paules, C.; Subbarao, K. Influenza. The Lancet. 2017, 390 (10095), 697-708.

https://doi.org/10.1016/S0140-6736(17)30129-0

42. Kim, H.; Webster, R. G.; Webby, R. J. Viral Immunol. 2018, 31 (2), 174-183. https://doi.org/10.1089/vim.2017.0141

43. Murakami, S.; Horimoto, T.; Ito, M.; Takano, R.; Katsura, H.; Shimojima, M.; Kawaoka, Y. J. Virol. 2011,86 (3), 1405-1410. https://doi.org/10.1128/JVI.06009-11

44. Duwe, S. GMS Infect. Dis. 2017, 5, Doc04.

https://doi.org/10.3205/id000030

45. Abed, Y.; Boivin, G. Open Forum Infect. Dis. 2017, 4 (3). https://doi.org/10.1093/ofid/ofx105

46. Gubareva, L. V.; Besselaar, T. G.; Daniels, R. S.; Fry, A.; Gregory, V.; Huang, W.; Hurt, A. C.; Jorquera, P. A.; Lackenby, A.; Leang, S. K.; Lo, J.; Pereyaslov, D.; Rebelo-de-Andrade, H.; Siqueira, M. M.; Takashita, E.; Odagiri, T.; Wang, D.; Zhang, W.; Meijer, A. Antiviral Res. 2017, 146, 12-20. https://doi.org/10.1016/i.antiviral.2017.08.004

47. O'Hanlon, R.; Shaw, M. L. Current Opinion in Virology. 2019, 35, 14-18. 
https://doi.org/10.1016/i.coviro.2019.01.006

48. Shiraki, K.; Daikoku, T. 2020, 209, 107512.

https://doi.org/10.1016/i.pharmthera.2020.107512

49. Bassetti, M.; Castaldo, N.; Carnelutti, A. Expert Opin. Pharmacother. 2019, 20 (14), 1711-1718. https://doi.org/10.1080/14656566.2019.1626824

50. Malakhov, M. P.; Aschenbrenner, L. M.; Smee, D. F.; Wandersee, M. K.; Sidwell, R. W.; Gubareva, L. V.; Mishin, V. P.; Hayden, F. G.; Kim, D. H.; Ing, A.; Campbell, E. R.; Yu, M.; Fang, F. Antimicrob. Agents Chemother. 2006, 50 (4), 1470-1479.

https://doi.org/10.1128/AAC.50.4.1470-1479.2006

51. von Itzstein, M. Nat. Rev. Drug Discov. 2007, 6 (12), 967-974. https://doi.org/10.1038/nrd2400

52. Air, G. M. Influenza Other Respi. Viruses 2012, 6 (4), 245-256. https://doi.org/10.1111/i.1750-2659.2011.00304.x

53. Macdonald, S. J. F.; Watson, K. G.; Cameron, R.; Chalmers, D. K.; Demaine, D. A.; Fenton, R. J.; Gower, D.; Hamblin, J. N.; Hamilton, S.; Hart, G. J.; Inglis, G. G. A.; Jin, B.; Jones, H. T.; McConnell, D. B.; Mason, A. M.; Nguyen, V.; Owens, I. J.; Parry, N.; Reece, P. A.; Shanahan, S. E.; Smith, D.; Wu, W. Y.; Tucker, S. P. Antimicrob. Agents Chemother. 2004, 48 (12), 4542-4549. https://doi.org/10.1128/AAC.48.12.4542-4549.2004

54. Macdonald, S. J. F.; Cameron, R.; Demaine, D. A.; Fenton, R. J.; Foster, G.; Gower, D.; Hamblin, J. N.; Hamilton, S.; Hart, G. J.; Hill, A. P.; Inglis, G. G. A.; Jin, B.; Jones, H. T.; McConnell, D. B.; McKimm-Breschkin, J.; Mills, G.; Nguyen, V.; Owens, I. J.; Parry, N.; Shanahan, S. E.; Smith, D.; Watson, K. G.; Wu, W. Y.; Tucker, S. P. J. Med. Chem. 2005, 48 (8), 2964-2971.

https://doi.org/10.1021/jm040891b

55. Watson, K. G.; Cameron, R.; Fenton, R. J.; Gower, D.; Hamilton, S.; Jin, B.; Krippner, G. Y.; Luttick, A.; McConnell, D.; MacDonald, S. J. F.; Mason, A. M.; Nguyen, V.; Tucker, S. P.; Wu, W. Y. Bioorganic Med. Chem. Lett. 2004, 14 (6), 1589-1592.

https://doi.org/10.1016/i.bmcl.2003.09.102

56. Yang, Z.-L.; Zeng, X.-F.; Liu, H.-P.; Yu, Q.; Meng, X.; Yan, Z.-L.; Fan, Z.-C.; Xiao, H.-X.; Iyer, S. S.; Yang, Y.; Yu, P. Tetrahedron Lett. 2016, 15-18. https://doi.org/10.1016/i.tetlet.2016.04.079

57. Fu, L.; Bi, Y.; Wu, Y.; Zhang, S.; Qi, J.; Li, Y.; Lu, X.; Zhang, Z.; Lv, X.; Yan, J.; Gao, G. F.; Li, X. J. Med. Chem. 2016, 59 (13), 6303-6312. https://doi.org/10.1021/acs.jmedchem.6b00537

58. Jokerst, J. V; Lobovkina, T.; Zare, R. N.; Gambhir, S. S. Nanoparticle PEGylation for Imaging and Therapy. Nanomedicine 2011, 6, 715-728.

https://doi.org/10.2217/nnm.11.19

59. Honda, T.; Yoshida, S.; Arai, M.; Masuda, T.; Yamashita, M. Bioorg. Med. Chem. Lett. 2002, 12 (15), 19291932.

https://doi.org/10.1016/S0960-894X(02)00330-X

60. Haldar, J.; Álvarez De Cienfuegos, L.; Tumpey, T. M.; Gubareva, L. V; Chen, J.; Klibanov, A. M. https://doi.org/10.1007/s11095-009-0013-1

61. Weight, A. K.; Haldar, J.; de Cienfuegos, L. Á.; Gubareva, L. V.; Tumpey, T. M.; Chen, J.; Klibanov, A. M. J. Pharm. Sci. 2011, 100 (3), 831-835. https://doi.org/10.1002/ips.22338 


\section{Authors' Biographies}

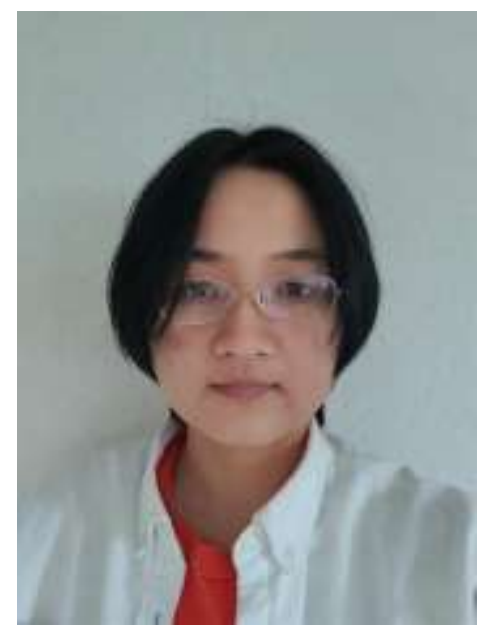

Xuan Wei studied medicinal chemistry at Shanghai Jiao Tong University, China (MSc. 2016). Xuan worked with Prof. Wanbin Zhang. In the winter of 2016, Xuan joined the Roland Pieters' group to do the research in discovering novel influenza inhibitors base on multivalent effecting.

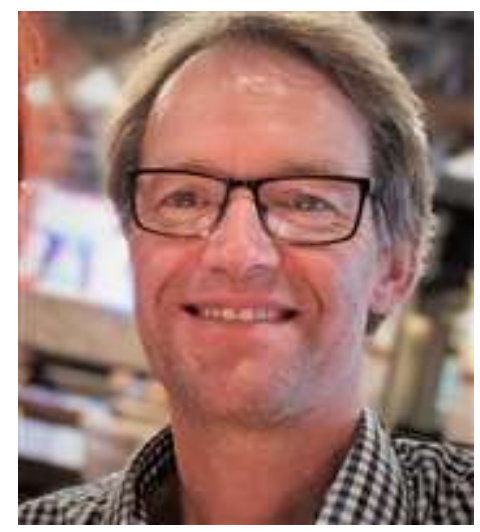

Roland Pieters studied organic chemistry at the University of Groningen, the Netherlands (MSc. 1990) where he worked with Prof. Ben Feringa and also as an exchange student at Trinity University in San Antonio (USA). He completed his Ph.D. at MIT with Prof. Julius Rebek Jr. in 1995 and was an NWO Talent post-doctoral at the ETHZürich with Prof. Francois Diederich. After another post doctoral stay (University of Groningen) he joined Utrecht University as an assistant professor in 1998 and obtained a fellowship from the Royal Netherlands Academy of Arts and Sciences and coordinated the EU project POLYCARB. He became an associate professor in 2005 , obtained a $\mathrm{VICl}$ grant in 2008, and was promoted to full professor in 2010 . His current research interests at the department of Chemical Biology and Drug Discovery are directed towards glycodrugs, by studying the interference with protein-carbohydrate interactions using multivalent systems of varying architectures including those with rigid spacers, for targets such as viral and bacterial adhesion proteins and toxins, galectins and glycosidases, Furthermore his group uses glyco- and peptide-microarrays in chemical biology and drug discovery e.g. on O-GIcNAcylation. 